Etnográfica

Revista do Centro em Rede de Investigação em

Antropologia

vol. 16 (3) | 2012

Vol. 16 (3)

\title{
Mutualidade e conhecimento etnográfico
}

Mutuality and ethnographic knowledge

\section{Susana de Matos Viegas e José Mapril}

\section{(2) OpenEdition}

\section{Journals}

\section{Edição electrónica}

URL: https://journals.openedition.org/etnografica/2104

DOI: 10.4000/etnografica.2104

ISSN: 2182-2891

\section{Editora}

Centro em Rede de Investigação em Antropologia

\section{Edição impressa}

Data de publição: 1 outubro 2012

Paginação: 513-524

ISSN: 0873-6561

\section{Refêrencia eletrónica}

Susana de Matos Viegas e José Mapril, «Mutualidade e conhecimento etnográfico», Etnográfica

[Online], vol. 16 (3) | 2012, posto online no dia 08 outubro 2012, consultado o 10 fevereiro 2022. URL:

http://journals.openedition.org/etnografica/2104 ; DOI: https://doi.org/10.4000/etnografica.2104

\section{(c) (i) (9)}

Etnográfica is licensed under a Creative Commons Attribution-NonCommercial 4.0 International License. 


\section{Mutualidade e conhecimento etnográfico}

\section{Susana de Matos Viegas e José Mapril}

Um dos mais difíceis desafios colocados a um antropólogo é o de explicar a uma audiência de colegas de diversas áreas disciplinares como é que no processo de trabalho de campo vamos reorientando a nossa análise, hipóteses e interpretações. Contrariando a ideia de que esta reorientação resulta de uma espécie de transcendência da produção etnográfica, onde os imprevistos seriam simples experiências autorais, neste texto, onde lançamos o debate deste dossiê, salientamos a dimensão processualista e intersubjetiva do conhecimento onde os imprevistos se integram: o facto de a etnografia se produzir no seio de relações sociais. A mutualidade aparece aqui como um aparato conceptual que descreve o tipo de interlocução - de "revelação partilhada" - que sustenta o próprio conhecimento etnográfico.

PALAVRAS-CHAVE: intersubjetividade, mutualidade, etnografia em antropologia, epistemologia.

Mutuality and ethnographic knowledge - It is commonly recognized that for anthropologists it is challenging to explain for an audience of scholars how the redirection of analysis occurs during fieldwork. Contrary to the idea that this reorientation results from a kind of transcendental principle where the unexpected is marginal, in this article, that launches this dossier, we contradict that idea of transcendence, calling attention to the processual and intersubjective nature of anthropological epistemologies - the fact that ethnography is constituted in relationships. Mutuality is here discussed as a conceptual tool that describes the specificity of those relationships - namely, the "shared revelation" - in the making of ethnographical knowledge.

KEYWORDS: intersubjectivity. mutuality, ethnography in anthropology, epistemo$\log$.

VIEGAS, Susana de Matos (susana.viegas@ics.ul.pt) - Instituto de Ciências Sociais da Universidade de Lisboa, Portugal.

MAPRIL, José (jmapril@gmail.com) - Centro em Rede de Investigação em Antropologia, Instituto Universitário de Lisboa - ISCTE-IUL, Portugal. 
O TERMO “MUTUALIDADE” TEM VINDO A SER USADO RECENTEMENTE para descrever o tipo de interlocução criada pelos antropólogos na situação de trabalho de campo, referindo-se ao "sentimento de revelação partilhada" que é incontornável na experiência da produção etnográfica sustentada em pesquisa de campo (Pina-Cabral no prelo). Na leitura de João de Pina-Cabral, a mutualidade funda o modo como "os antropólogos e os informantes se envolvem em processos de (co)responsabilidade”, correspondendo a uma aproximação à comunicação antropológica, articulada em ações (Pina-Cabral 2003, no prelo; Davidson 2001). ${ }^{1}$

Como refere Richard Wilson a propósito do pensamento de Pina-Cabral, o que está em causa é reconhecer que o conhecimento etnográfico se funda em processos de comunicação que implicam cedências mútuas e por isso são melhor descritos a partir de conceitos como o de "caridade interpretativa" do filósofo analítico Donald Davidson, do que tendo por referência conceitos como o de "tradução", criados para descrever a transposição de sentidos linguísticos (Wilson 2004: 15). Richard Wilson lembra que o conceito de "caridade interpretativa" serve para explicar trânsitos históricos que, por exemplo, permitem a comunicação entre mundos muito diferentes, quando chineses se interessam pelos romances literários ocidentais "e mergulharam nos valores e nos mundos que eles representam", ou quando Peter Brook adapta a épica indiana do Mahabharata a peças teatrais que podem ser desfrutadas e que se impregnam no pensamento intelectual dos espectadores euro-americanos (Wilson 2004: 16). Pina-Cabral insiste igualmente neste fundo histórico de influências mútuas, assinalando como "para várias gerações de chineses e chinesas a leitura de Balzac, Flaubert, Roman Rolland ou Gide não foi uma simples distração, mas constituiu um instrumento para o reenquadramento do seu quadro referencial mais vasto em termos das suas identidades pessoais enquanto intelectuais, enquanto cidadãos mas, sobretudo, enquanto homens e mulheres" (Pina-Cabral 2003: 113 ).

Ao transferir esse conceito de "caridade interpretativa" para a produção da etnografia em antropologia, Pina-Cabral acredita que também a origem do projeto de conhecimento antropológico assenta num processo de procura de pontos de contacto e dos sentidos que nos aproximam dos nossos interlocutores, ainda que procure a compreensão da diferença (uma marca incontornável da antropologia):

1 Este debate foi iniciado em 2009 quando desafiámos os participantes numa sessão do Congresso da Associação Portuguesa de Antropologia para desenvolverem as suas ideias sobre a etnografia e o imprevisto. Foi, no entanto, quando enquadrámos o tema no que Pina-Cabral tem vindo a chamar "mutualidade" que o projeto acabou por tomar forma. Por isso, o debate remete necessariamente para o pensamento deste autor. A interlocução com João de Pina-Cabral substantivou-se ainda durante as discussões havidas em torno ao projeto conjunto “A Trama Territorial” (PTDC/CS-ANT/102957/2008). 
"Voltemos às conceções de Donald Davidson sobre o processo de comunicação. Para este autor a 'indeterminação da tradução' só é ultrapassada pelo fato de estarmos dispostos a conceder aos nossos interlocutores que o que eles dizem é passível de fazer sentido. A esta disposição ele chama 'caridade interpretativa'" (Pina-Cabral 2003: 118).

Rejeitando há muito a utilidade da metáfora da "tradução" para explicar ou descrever os termos da intermediação na etnografia (Pina-Cabral 1991), a influência primeiro de Davidson e depois de uma leitura e adaptação das reflexões de Johannes Fabian marca a proposta de João de Pina-Cabral, segundo a qual a mutualidade é o eixo processual que marca a produção etnográfica contemporânea. Essa proposta implica pelo menos três posicionamentos face ao conhecimento antropológico. Primeiro, conceber a pesquisa de campo como um processo não tanto subjetivo (como sublinharam as reflexões pós-modernas) mas intersubjetivo - o que obriga a repensar essa dimensão do conhecimento. Em segundo lugar, reintegrar e refundar os conceitos de "real", "verdade" ou "evidência" para o projeto de conhecimento antropológico: "É importante continuarmos a insistir que, na etnografia, podemos capturar o real" (Pina-Cabral 2010: 167). Este pragmatismo tem marcado muitas das reflexões contemporâneas recentes sobre o tema na antropologia (por exemplo, Csordas 2004; Hastrup 2004; Wilson 2004; Strathern 2006; Bloch 2008; Engelke 2008; Toren e Pina-Cabral 201 1). Em terceiro lugar, tomarmos a mutualidade como condição para esta "verdade" antropológica, assumindo que integramos as formulações discursivas sobre a vida nas experiências e modos como o mundo se vai configurando, permite ultrapassar o falso, mas tão difundido, axioma segundo o qual o propósito da antropologia seria o de confrontar o que se diz com o que se faz ou pensa:

"Partindo da constatação de que o mundo vivido é historicamente constituído, os antropólogos foram frequentemente tentados a considerar que o que havia para analisar era apenas esse mesmo processo constitutivo; isto é, que não há mundo (that there is no world)" (Pina-Cabral 2010: 167).

Diferentemente dessa visão discursivista extrema, a ideia de que a produção da etnografia depende da capacidade de criar condições de mutualidade obriga a perguntar o que há de partilhável em relações à partida inverosímeis, tais como as que vivemos em contextos de pesquisa etnográfica. A partilha não significa, portanto, assentir e, sim, alcançar pontos de comunicação - de semelhança e não de identidade -; não implica também que os nossos interlocutores alcancem connosco e ao mesmo tempo do que nós o conhecimento que nós alcançamos, até porque produzimos o nosso conhecimento em diálogo com uma tradição de conhecimento, com debates específicos, que 
se consolidaram no decorrer de uma história disciplinar (Pina-Cabral 2003: 109). Por não ser um conhecimento homogéneo, já que ele implica, necessariamente, uma diversidade de perspetivas (multivocal, plural, etc.) que se vão constituindo num processo temporal longo, a produção de conhecimento etnográfico implica também uma permanente reavaliação do conhecimento face a sucessivas interlocuções. A ideia está bem representada na expressão de Fabian de que em trabalho de campo "não consumimos os outros", porque os nossos interlocutores "permanecem presentes e confrontam-nos" (Fabian 2001: 77, cit. em Pina-Cabral no prelo).

A mutualidade é, assim, uma chave para a epistemologia etnográfica. Um dos mais difíceis desafios colocados a um antropólogo é explicar a uma audiência de colegas de diversas áreas disciplinares em que medida e como é que, no processo de trabalho de campo, vamos reorientando a nossa análise, as nossas hipóteses e as nossas interpretações. Quanto mais o contexto universitário caminha para exigências de estandardização, mais a questão se coloca. E quanto mais diversas áreas do conhecimento adotam preferências por abordagens etnográficas - da psicologia à sociologia ou à criminologia -, mais difícil se torna mantermos a ideia de que um projeto de pesquisa antropológica não tenha de partir de "hipóteses". Do ponto de vista da antropologia, a ideia de que a etnografia assenta num método através do qual se recolhem dados objetivos no/do terreno não está em causa, mas a forma como se concebe essa aproximação ao terreno por vezes implica ou tende a implicar uma ficção de distância e, ao mesmo tempo, de transcendência no processo de construção do conhecimento. Para contrariar essa transcendência que torna nebulosa a descrição do processo de produção de conhecimento etnográfico é preciso não negligenciar a dimensão processualista do conhecimento, em constante transformação e que se produz no seio de relações sociais. A reflexão que propomos neste dossiê contribui para dar resposta a este conjunto de desafios, partindo da premissa de que a experiência da situação de campo não implica apenas para a antropologia uma vivência pessoal (subjetiva) e, sim, uma vivência prolongada de intersubjetividade que se desenvolve por meio de revelações partilhadas, sendo no âmbito dessas revelações que vamos reformulando as próprias categorias com que compreendemos a realidade em estudo (Toren e Pina-Cabral 2011; Toren 2011 ; Viegas 2011).

Assim, o contributo deste dossiê para estas questões resultou, primeiramente, do desafio que fizemos a cada um dos autores para refletir sobre uma situação ocorrida no decurso da sua pesquisa de campo que tivesse sido por eles considerada um "imprevisto" (esta foi a expressão que usámos). Reforçámos o facto de não se tratar de contar uma "anedota" de campo ou de expor um momento difícil para o autor, mas de explorar um ou mais eventos que tivessem representado uma experiência inesperada por meio da qual tivessem reformulado as perguntas etnográficas. Os textos que integram o dossiê 
respondem de modos muito diversos, e ao mesmo tempo complementares, a este desafio.

As investigações de campo desenvolvidas pelos antropólogos que contribuíram para este dossiê constituem, do nosso ponto de vista, uma importante representação da diversidade das investigações antropológicas que estão atualmente a ser desenvolvidas sobre Portugal - a revisitação do mundo rural, o acompanhamento de vidas transnacionais, a produção (e poder) de identidades profissionais, as reequações das pertenças e papéis de género em contexto imigratório. Nesse sentido, o conjunto dos artigos deste dossiê leva-nos a realidades do país, contribuindo para a constante atualização dos terrenos portugueses e para a compreensão das suas complexidades (e.g. O’Neill e Brito 1991; Lima e Sarró 2006).

\section{MUTUALIDADE E INTERSUBJETIVIDADE}

"Para a antropologia a etnografia permanece vital, não porque os métodos etnográficos garantam um certo tipo de conhecimento dos outros, mas porque o trabalho de campo etnográfico nos leva a um diálogo direto com os outros, oferecendo-nos oportunidades para explorar o conhecimento" (Jackson 1996: 7).

A mutualidade como marca do processo de produção da etnografia implica tomar a posição do sujeito e a subjetividade como intersubjetividade (Toren 2011; Viegas 2011), dando um passo em frente na integração da problemática da reflexividade na antropologia. Como nos lembra Hastrup, se na "era moderna" se admitia que o objetivo do conhecimento antropológico era a enumeração de proposições ontológicas sobre "outras culturas", a antropologia produzida após a crítica reflexivista será informação organizada, sim, mas direcionada aos "modos de viver no mundo e modos de atender ao mundo" (Hastrup 2004: 456), fazendo da condição de ser-no-mundo o ponto de partida para a pesquisa antropológica (Pina-Cabral e Campbell 1992; Toren 1993; Jackson 1996: 9). Numa recente reflexão sobre as adaptações da intersubjetividade da filosofia fenomenológica (especificamente de Husserl) para a antropologia, Alessandro Duranti (2010) lembra-nos que esta adaptação da fenomenologia ao projeto de conhecimento antropológico só se tornou possível porque a antropologia se libertou do tipo psicologizante das abordagens da intersubjetividade (Devereux 1967), que a entendem como uma forma de "conhecer o que os outros têm em mente" ou "uma experiência de participar nas ações e sentimentos de outro ser, sem se ser ou nos tornarmos o outro" (Duranti 2010: 19, 22). No seguimento do pensamento de Husserl, Duranti expõe um outro modo de conceber a intersubjetividade que, em vez de a aproximar da empatia ("ver o mundo do ponto de vista do Outro"), 
a descreve como uma condição de produção de saber necessariamente vinculada à relação: "ver a intersubjetividade de uma forma verdadeiramente husserliana significa concebê-la, antes de tudo, como a possibilidade da interação humana e do conhecimento humano" (Duranti 2010: 21, 26). A relação, neste sentido, não pode ser confundida com a identificação (que a empatia presumia).

É esta depuração conceptual da intersubjetividade que está associada à noção de mutualidade. Ela distingue-se, por fim, de uma outra aceção de mutualidade proposta recentemente por Marshall Sahlins a propósito do parentesco, que poderia ser definida como a "mutualidade do ser" (mutuality of being): uma relação entre pessoas que "pertencem [belong] umas às outras, que são parte umas das outras, que estão copresentes umas nas outras, cujas vidas estão juntas e são interdependentes" (Sahlins 201 l: 1 l). Esta proposta de Sahlins não se alinha diretamente com o entendimento da intersubjetividade que aqui postulamos. Sahlins está a recorrer à visão da intersubjetividade como uma forma de participação entre duas entidades separadas. Diferentemente, a perspetiva que aqui defendemos presume que a própria subjetividade é intersubjetividade e portanto a "revelação partilhada", a rigor, é constitutiva e não o produto da aproximação entre dois entes. ${ }^{2}$

A fundamentação do trabalho epistemológico da antropologia nesta experiência de mutualidade tem um último corolário que apenas enunciámos acima e que importa explicitar. Se, por um lado, a mutualidade implica uma corresponsabilidade e, por outro, implica um confronto permanente (e não determinável) com os nossos interlocutores, então se compreende a complexidade da ética no empreendimento da pesquisa antropológica. Se estamos permanentemente a ser confrontados com os outros e se faz parte do projeto de conhecimento antropológico integrar esse confronto no nosso conhecimento, então a ética é um procedimento que acompanha do início ao fim o trabalho de pesquisa. Percebemos, no próprio procedimento epistémico, por que razão se tem tornado tão dominante a ideia de que, no caso da antropologia, os consentimentos prévios não resolvem as questões éticas (por exemplo, Caplan 2003: 23). Afinal, e como Michael Lambek (2010) argumentou recentemente, os discursos e as ações dos sujeitos encerram uma ética banal (ordinary ethics, no original), ética essa que, como argumentamos, está presente, em toda a sua complexidade e ambiguidade, nas formas como construímos conhecimento na relação com os nossos interlocutores.

Sumariando o propósito deste dossiê, poderíamos dizer que a pesquisa antropológica implica uma forma de experiência intersubjetiva que não é

2 Na verdade, a discussão sobre os pontos de convergência e afastamento entre os entendimentos de mutualidade por Fabian e Sahlins é um dos propósitos do texto de Pina-Cabral (no prelo) que serve de referência a este dossiê. 
apenas um meio (um método) para alcançar um fim (conhecimento), mas uma forma efetiva de criar/produzir conhecimento. É esse percurso, do reflexivismo metodológico para aquilo a que poderíamos aqui chamar reflexivismo epistémico, que é percorrido em cada um dos textos deste dossiê. A marca deste tipo de reflexão passa por descrever como se transforma em conhecimento as reações imprevistas de interlocutores em campo, nesse sentido contribuindo para essa ampla e inacabada tarefa de explicarmos porque a antropologia não parte de hipóteses e sim de problematizações. A integração de reações imprevistas serve aqui de mote, portanto, para descrevermos como se transforma o confronto mútuo em material que, por sua vez, moldamos e transformamos em conhecimento.

\section{CONHECIMENTO E REVELAÇÃO \\ EM QUATRO EXPERIÊNCIAS DE PESQUISA ETNOGRÁFICA}

Este dossiê conta com quatro textos que explicitam a produção de etnografias fundadas em experiências de campo. No primeiro texto, Humberto Martins fala-nos de uma região rural do Norte de Portugal - um contexto que nos diz ter sido escolhido por ele porque "o mundo rural português oferece no século XXI objetos de estudo novos e interessantes". Desenvolvendo uma pesquisa que alia etnografia escrita com filme etnográfico, Humberto Martins situa a sua pesquisa num registo explícito de mutualidade: "Ela reconhece a importância de um plano, de uma sequência numa cozinha antiga, escura do fumo de anos a curar o fumeiro, da sua representação em imagem criada simultaneamente por mim e por ela e da representação que muitos outros espectadores criarão sobre aquele lugar, ela, eu". Dar a sua opinião sobre qualquer assunto que surgisse na sua interlocução em campo era portanto a posição que viria a assumir sem hesitação, esperando que as reações dos seus interlocutores fossem parte da sua compreensão desta vida rural no século XXI.

Assim surgiram as reações inesperadas face a duas opiniões que esboçou, tendo sido por intermédio dessas reações que foi compreendendo experiências vividas pelos habitantes locais. A primeira correspondeu a uma reação negativa à opinião que expressou a propósito da "passagem do gado bovino nas ruas calcetadas (principais) do povoado". Reconhecendo a diversidade de perspetivas sobre o assunto, o antropólogo acaba por se posicionar do lado de algumas das pessoas da aldeia "que acham que a aldeia deve manter a sua originalidade, ou seja, a sua vida e estética camponesa, o que, curiosamente, se torna objeto de desejo do turismo predominante no Parque Nacional da Peneda-Gerês (onde a aldeia se situa)". Face à sua posição, as reações multiplicam-se e expõem-se as posições ambivalentes dos moradores que fazem parte de um mundo rural marcado pela modernidade. Tendo experienciado no passado (quando emigrados) viver em espaços limpos e isentos de odores de bovino, estes moradores 
contrapõem-se, defendendo que "o gado e, em geral, todos os animais (galinhas, pintos, cabras, ovelhas e cavalos) deviam apenas passar pelos caminhos à volta do aglomerado urbano". Um dos seus próximos interlocutores considerou que, ao estar contra esta posição, o antropólogo não estaria verdadeiramente implicado na vida quotidiana da aldeia, projetando-o para fora ("tu não és daqui”). É a partir dessa reação que Humberto Martins funda a sua compreensão do que significa a ambivalência de um rural confrontado com as aporias do mundo moderno.

Irene Rodrigues fala-nos de uma pesquisa que, nos últimos dez anos, a tem levado a conviver com chineses em Lisboa, em Pequim e numa área rural chinesa. Percorrendo as diversas formas como foi sendo por eles posicionada no contexto de uma mesma categoria de "estrangeira" (laowai), vai depurando um exercício reflexivo que tem por objetivo aprofundar o conhecimento etnográfico do que é ser estrangeira. As posições dos seus interlocutores confrontam-na permanentemente e com elas vai aprendendo não apenas a prosseguir em campo, mas também a refletir sobre esta condição de ser estrangeiro e do "etnógrafo estrangeiro na China", que as reflexões antropológicas só têm referido de modo pontual "a propósito dos entraves políticos e formais à obtenção de autorização para a realização da investigação, e das reorientações temáticas que daí advieram". Diferentemente dessa postura estritamente autorreflexiva, o texto de Rodrigues leva-a a aprofundar a multiplicidade de sentidos da condição de laowai num amplo quadro social que transita entre considerações sobre ser-se estrangeiro na China e dar-se com estrangeiros entre os emigrados fora da China: "a ideia de estrangeiro difundida na China tem fortes continuidades e nuances históricas, já que ela não reflete apenas o modo como são percecionados os 'ocidentais' na China, mas também o sentido de modernidade na China e a própria ideia de ser chinês na atualidade”.

Se para alguns dos seus interlocutores Irene Rodrigues conseguia em momentos determinados "quase" parecer pelo menos parente de chineses, conclui haver também quem continue a mantê-la como estrangeira e, na verdade, descobre desse modo que há um sentido positivo que é atribuído pelos chineses emigrados em Portugal ao facto de se estar com um estrangeiro: "Nalgumas situações, aparecer com uma amiga 'estrangeira' era capitalizado pelos chineses que eu acompanhava, perante outros chineses, como uma forma de promover a sua mobilidade social ascendente". Para desbravar esse conhecimento etnográfico, a análise de Irene Rodrigues vai procurando outras categorias que ajudem a compreender o espetro de sentidos desta categoria (afinal lata) de ser laowai, por exemplo aquelas que se fundamentam na origem territorial e social: "Um dia em conversa com um outro amigo chinês, estudante de inglês oriundo da província de Jiangxi, ele avisou-me: 'Agora tens de ter muito cuidado a andar em Pequim. A cidade está cheia de waidiren (gente de fora)!" A transposição de uma reflexão metodológica 
e autorreferencial para um registo da produção do conhecimento etnográfico (a que aqui chamamos reflexivismo epistémico) é portanto iluminadora no texto de Irene Rodrigues.

Elizabeth Challinor (cujo contributo surge num texto em inglês, dado ser essa a língua-mãe da autora) define o seu posicionamento em campo como um envolvimento de simultâneo alheamento e intimidade. Discutindo "duas dimensões da [sua] investigação com mulheres cabo-verdianas estudantes numa cidade no Norte de Portugal", Elizabeth Challinor descreve neste texto a transformação do que se propunha estudar e a necessária reformulação das suas categorias de pesquisa, face a dois aspetos do trabalho de campo que, afirma, "me levaram não só a reconsiderar a minha própria posição, como a reajustar as lentes analíticas através das quais tinha estabelecido os terrenos da minha pesquisa, nomeadamente as categorias de mulheres cabo-verdianas e as dinâmicas de poder entre géneros". Se à partida pretendia estudar as mães, a sua gravidez marcada pela fragilidade de uma situação de emigrantes, jovens e eventualmente sem parceiro conjugal, a pesquisa de campo vai-a conduzindo a uma muito mais complexa trama de entendimento das relações de género, das dinâmicas de poder e das mudanças vividas por mulheres e homens nas circunstâncias em que se encontram. Este salto é configurado no artigo que aqui nos apresenta a partir de um evento que para ela foi um choque experiencial imprevisto, já que se viu envolvida numa desavença conjugal com contornos que vão indiciando a eventual presença de violência doméstica.

O texto centra-se na difícil descrição de como o choque deste episódio a conduziu a um "choque" epistémico, tendo de romper com categorias centrais à sua pesquisa, tais como a fragilidade da maternidade entre jovens mulheres emigradas, para dar conta de dilemas complexos das dinâmicas de género que descobre estarem em processo de transformação. Assim, se a sua atitude inicial face às posições opostas de cada um dos cônjuges foi a de proteger a mulher grávida ("o foco da minha pesquisa implicava que fosse particularmente sensível à situação das mulheres grávidas nas suas potenciais fragilidades emocionais e físicas"), o artigo acaba por nos dar conta da sua mudança de perspetiva, não tanto por contingências de método, mas por avanços na compreensão (e integração) das vidas destas mulheres num mundo complexo de relações de género, marcado por fortes ambivalências e dilemas vividos por homens e mulheres cabo-verdianas nestas circunstâncias. O processo de conhecimento marcado pelo que denomina "conviver com a tensão" (staying with the tension) conduz a observações complexas sobre diferentes paradigmas de género que parecem estar a ser experienciados ao mesmo tempo por homens e mulheres cabo-verdianos, devido a "influências opostas de ideologias de género divergentes que produzem uma variedade de expetativas de género que coexistem pouco harmoniosamente". O texto expõe de modo particularmente iluminador como relações de mutualidade desencadeiam reformulações do enfoque analítico e 
o alcance ambivalente de vivências que parecem "encravadas" entre diferentes ideologias.

Madalena Patriarca mostra como, no decorrer da realização do seu trabalho de campo em Lisboa sobre os psiquiatras, se confrontou com entraves de natureza ética e epistemológica à observação dos serviços psiquiátricos. Tais entraves revelavam não apenas uma desconfiança de muitos dos seus interlocutores quanto à abordagem etnográfica, mais concretamente em relação à sua "fiabilidade científica", mas revelavam também o cerne mesmo daquilo que a psiquiatria considera ser o conhecimento científico legítimo. A antropóloga percebeu que os consentimentos que havia conseguido para realizar pesquisa sobre psiquiatras nos hospitais de Lisboa se revelaram pouco úteis para o que efetivamente era preciso para os psiquiatras a posicionarem e lhe reconhecerem legitimidade (ética) para a sua investigação. Os psiquiatras duvidam substantivamente do tipo de "recolha de dados" que ela se propõe fazer e assim mostra-nos como isso passou a fazer parte constitutiva do seu conhecimento sobre a psiquiatria. É, portanto, ao integrar as perspetivas deles sobre o seu trabalho que ela própria vai desvelando o seu objeto de estudo. Estes imprevistos do terreno conduziram a autora a caminhos alternativos que resultaram na produção de uma cartografia histórico-psiquiátrica da cidade.

Contámos finalmente com um contributo especial de Fernando Florêncio, na sequência da sua participação como discussant no primeiro seminário que esteve na origem desta publicação. Entusiasmado em refletir sobre a sua própria experiência de produção etnográfica, o texto de Florêncio serve-nos quase de contraponto aos restantes contributos. Sustentando-se em trabalho de campo de longa duração realizado em Moçambique e lidando com questões da política, particularmente acesas do ponto de vista de éticas e mutualidade, Florêncio conduz-nos a pensar nas implicações de se trabalhar um tema para o qual a interlocução em campo é condição de base para contrariar posições ideológicas. Mostra-nos, ao mesmo tempo, os difíceis contornos desse processo neste caso, tanto da questão política como da sua condição de estrangeiro num país com passado colonial. A interlocução, intersubjetividade e mutualidade ganham nesse contexto uma expressão quase de "teste" à abrangência da problemática da produção do conhecimento etnográfico tal como a debatemos aqui, mostrando a sua natureza altamente contingente e pragmática.

O conjunto de textos reunidos neste dossiê temático é, em suma, uma concretização exemplar do enquadramento da etnografia contemporânea realizada por antropólogos que fizeram pesquisa de campo na última década e viram nessa experiência uma materialização de um conhecimento que transformou a subjetividade da experiência de campo em intersubjetividade, e também os imponderáveis das suas experiências de campo em processos de interlocução marcados pela mutualidade. 


\section{BIBLIOGRAFIA}

BLOCH, Maurice, 2008, "Truth and sight: generalizing without universalizing", Journal of the Royal Anthropological Institute, n. s., 14 (S1): S22-S32.

CAPLAN, Patricia, 2003, The Ethics of Anthropology: Debates and Dilemmas. Londres, Routledge. CSORDAS, Thomas J., 2004, "Evidence of and for what?", Anthropological Theory, 4: 473$-480$

DAVIDSON, Donald, 2001, Inquiries into Truth and Interpretation. Oxford, Oxford University Press.

DEVEREUX, Georges, 1967, From Anxiety to Method in the Behavioral Sciences. Haia, Mouton.

DURANTI, Alessandro, 2010, "Husserl, intersubjectivity and anthropology", Anthropological Theory, 10 (1-2): 16-35.

ENGELKE, Matthew, 2008, “The objects of evidence”, Journal of the Royal Anthropological Institute, n. S., 14 (S1): S1-S21.

FABIAN, Johannes, 2001, Anthropology with an Attitude: Critical Essays. Stanford, Stanford University Press.

HASTRUP, Kirsten, 2004, "Getting it right: knowledge and evidence in anthropology". Anthropological Theory, 4 (4): 455-472.

JACKSON, Michael, 1996, "Introduction: phenomenology, radical empiricism and anthropological critique”, em Michael Jackson (org.), Things As They Are: New Directions in Phenomenological Anthropology. Bloomington e Indianapolis, Indiana University Press, $1-50$.

LAMBEK, Michael (org.), 2010, Ordinary Ethics: Anthropology, Language and Action. Nova Iorque, Fordham University Press.

LIMA, Antónia Pedroso de, e Ramon SARRÓ (orgs.), 2006, Terrenos Metropolitanos: Ensaios sobre Produção Etnográfica. Lisboa, Imprensa de Ciências Sociais.

O’NEILL, Brian Juan, e Joaquim Pais de BRITO (orgs.), 1991, Lugares de Aqui: Actas do Seminário “Terrenos Portugueses". Lisboa, Publicações Dom Quixote.

PINA-CABRAL, João de, 1991, "Contra a tradução”, em João de Pina-Cabral, Os Contextos da Antropologia. Lisboa, Difel, 43-68.

PINA-CABRAL, João de, 2003, "Semelhança e verossimilhança: horizontes da narrativa etnográfica”, Mana, 9 (1): 109-122.

PINA-CABRAL, João de, 2010, "The door in the middle: six conditions for anthropology", em Deborah James, Evie Plaice e Christina Toren (orgs.), Culture Wars: Context, Models and Anthropologists' Accounts. Nova Iorque e Oxford, Berghahn Books, 152-169.

PINA-CABRAL, João de, no prelo, "The two faces of mutuality: contemporary themes in anthropology", Anthropological Quarterly, 86 (1).

PINA-CABRAL, João de, e John CAMPBELL, 1992, "Introduction”, em João de Pina-Cabral e John Campbell (orgs.), Europe Observed. Hampshire e Londres, Macmillan Press, X-XIII.

SAHLINS, Marshall, 2011 , "What is kinship (part one)", Journal of the Royal Anthropological Institute, n. s., 17: 2-29.

STRATHERN, Marilyn, 2006, "A community of critics? Thoughts on new knowledge", Journal of the Royal Anthropological Institute, n.s., 12: 191-209.

TOREN, Christina, 1993, "Making history: the significance of childhood cognition for a comparative anthropology of mind", Man, 28: 461-478. 
TOREN, Christina, 2011 , "Intersubjectivity as epistemology", em Christina Toren and João de Pina-Cabral (orgs.), The Challenge of Epistemology: Anthropological Perspectives. Oxford e Nova Iorque, Berghahn Books, 130-146.

TOREN, Christina, e João de PINA-CABRAL, 201 1, "Introduction: the challenge of epistemology", em Christina Toren e João de Pina-Cabral (orgs.), The Challenge of Epistemology: Anthropological Perspectives. Oxford e Nova Iorque, Berghahn Books, 1-18.

VIEGAS, Susana de Matos, 2011, "Can anthropology make valid generalizations? Feelings of belonging in the Brazilian Atlantic Forest", em Christina Toren and João de Pina-Cabral (orgs.), The Challenge of Epistemology: Anthropological Perspectives. Oxford e Nova Iorque, Berghahn Books, 147-162.

WILSON, Richard A., 2004, “The trouble with truth: anthropology's epistemological hypochondria”, Anthropology Today, 20 (5): 14-17. 